\title{
The role of inhibition capacities in the lowa gambling test performance in young tattooed women
}

\author{
Semion Kertzman ${ }^{1,2^{*}} \mathbb{D}$, Alex Kagan ${ }^{3,4,5+}$, Omer Hegedish ${ }^{1,6}$, Rina Lapidus ${ }^{7}$ and Abraham Weizman ${ }^{2,8}$
}

\begin{abstract}
Background: Using the lowa Gambling Test (IGT), we demonstrated previously impaired decision- making process in young tattooed women. The purpose of the present study was to explore the associations among the three facets of impaired inhibition (response inhibition, reflection inhibition and interference inhibition) and decisionmaking processes in this population.

Methods: To this end, the participants of the previous study (60 tattooed women and 60 non-tattooed women) were assessed in the Go/NoGo task, a measure of response inhibition, the Matched Familiar Figure Test (MFFT), a measure of reflection inhibition and the Stroop task a measure of interference inhibition.

Results: Tattooed women were significantly slower than non-tattooed women in the Go/NoGo performance; however, no differences were detected in the MFFT and the Stroop task. A hierarchical regression analysis did not reveal any significant main effects of these inhibition measures on the IGT performance.

Conclusions: These findings do not support the hypothesis that risky decision in young tattooed women is due to impaired inhibitory control. Further studies are needed to identify the cognitive mechanisms involved in the tendency to risky decisions in young tattooed women.
\end{abstract}

Keywords: Tattoo, IGT, Inhibition, Impulsivity

\section{Background}

Young people are likely to engage in risky behaviors, such as drinking alcohol, taking illegal drugs, having unprotected sex, engaging in delinquent activity, and driving recklessly [1]. Empirical research found association between getting tattoos and higher frequency of these behaviors, as well as, to engage in illegal activities, problem gambling, dropping out of school, suicidal attempts, violence and death by homicide [2-4]. It possible that young people, who have tattoos is more open to engaging in risk-behavior [5-16] Although, it was previously shown that young individuals with tattoo display worse performance in decision-making tasks such the Iowa Gambling Task (IGT) [17] and elevated self-

\footnotetext{
* Correspondence: kertzman@animascan.com

†'Semion Kertzman and Alex Kagan contributed equally to this work.

'Beer-Ya'akov-Ness Ziona Mental Health Center, Forensic Psychiatry Division, Ness Ziona, Israel

${ }^{2}$ Sackler Faculty of Medicine, Tel Aviv University, Tel Aviv, Israel

Full list of author information is available at the end of the article
}

assessed impulsiveness $[17,18]$, the relation between the constructs in tattooed population was not analyzed. The decision making is a complex process, and understanding the role of more detailed cognitive processes such inhibition abilities responsible for risky decisions remains unclear. Findings from previous studies on this issue in non-tattooed samples were inconsistent. The mechanisms of risky behavior may be clarified by analysis of the interactions between decision making and inhibition abilities [19]. However, research on the association between decision making and inhibition abilities is inconsistent. Some studies claim that the inhibition abilities is an integral part of decision-making process and is aimed to protect a decision process from disruption by competing events of information streams [20-22] In addition, inhibition training was proved to be effective in reducing decision making errors [23]. In contrast, other studies suggest that decision making process is not in close association with inhibition abilities and propose

(c) The Author(s). 2019 Open Access This article is distributed under the terms of the Creative Commons Attribution 4.0 International License (http://creativecommons.org/licenses/by/4.0/), which permits unrestricted use, distribution, and 
complex interactions between biases, reasons, emotions, goals, motivations, competing resources and opportunities afforded by the social context [24, 25]. Moreover, some authors found that inhibition capacity can be dissociated from risky decision [26-31]. For example, it was found that excessive internet users have deficits in decision-making function, which are characterized by a strategy learning lag rather than an inability to learn from a task contingencies and their risky decisions are not related to response inhibition abilities [32]. Furthermore, it was demonstrated that sleep deprivation diminished initial prepotent inhibition but not the decision making process [33]. An animal study also demonstrated that inhibition and risk taking decision are separate processes [34].

Thus, it is unclear whether tattooing behavior can be independently predicted by a weak inhibitory control or risky decisions or both. The current study attempts to answer two main issues:

1) Are tattooed women exhibit risky behavior as a result of impaired inhibition capacities? It should be noted that inhibition is a complex concept. Bari and Robbins [35] suggested dividing inhibitory control into two categories: behavioral or response inhibition and cognitive inhibition or resistance to distractor interference. In addition, Kagan [36] introduced the concept of reflection inhibition as a capacity to choose the correct course of action from a number of possibilities prolonging the time before action is taken. We assessed these three inhibition capacities in an attempt to identify which inhibition facet is associated with getting tattoo.

2) Is there an effect of inhibition capacities on decision making process in young women with tattoo? It is expected that in tattooed population there is an association between risky decision and limited inhibition resources. The current study attempted to analyze influence of different inhibition mechanisms on the IGT performance in a sample of tattooed young women assumed to exhibit high level of impulsivity trait compared to a non-tattooed population [17, 18, 37, 38]. We assumed that risky decisions are associated differently with inhibition capacities in women with high impulsivity (tattooed) compared to those with low impulsivity (non-tattooed controls).

To our knowledge, there are no studies on the evaluation of inhibition capacities among tattooed population and the relation between decision-making process and inhibition capacities in women with tattoos.

\section{Methods}

As described in previous publications $[17,39]$ the entire research process took five months (March-July 2012), and included locating candidates for the study in the Tel Aviv area, through advertising at universities, in social networks (Facebook) and using personal contacts. Women (research and control), with and without tattoos, from similar socio economic backgrounds (employed, students or graduates) were invited to apply to be part of a research project authorized by Bar-Ilan University Review Board (Ramat Gan, Israel) focusing on the decision making process of both groups. Prior to being accepted to the study, all participants underwent an evaluation to determine their eligibility, which included questions on medical history, illicit drug use, family and personal psychiatric history. All were free of any psychopharmacologic treatment. The 120 women (who were also part of our study on the association between tattooing behavior and risky decisions as reflected in IGT) signed a consent form to be part of a free study and in return receive a complimentary consultation regarding their inhibition capacity and professional guidance about their neurocognitive and personality assessments. The individual sessions (up to $90 \mathrm{~min}$ each), also included a detailed description of the research aims.

The link between risky decision and inhibition capacities was analyzed using three laboratory measures.

A semi-structured interview [17] with a 20-item measure of tattoo characteristics was conducted by a researcher (AK) for 60 tattooed women (no men to prevent sex differences on the cognitive measures, or women who had removed tattoos) aged 18-35 $(\mathrm{M}=28.4, \mathrm{SD}=5.95)$, with no neurological disorders, mental retardation, and no record of substance abuse/dependence (other than smoking). All were employed or students, $58 \%$ had more than one tattoo, all were employed or students: high school diploma or lower 46.7\%, bachelor's degree: $25 \%$, master's degree $23.3 \%$ and philosophy: $5 \%$. Of this entire group of tattooed women, $55 \%$ were smokers.

The 60 non-tattooed women (control group) did not include anyone with current or past DSM-IV-TR axis I psychiatric disorder. Participants were of similar ages, 18-35 $(\mathrm{M}=28.5, \mathrm{SD}=5.43)$. The education level for this group was as follows: high school diploma or lower $-25 \%$, first university degree $-28.3 \%$, second university degree $-41.7 \%$ and philosophy degree $-5 \%$. The percentage of smokers in this group was only $10 \%$.

We used one decision-making measure (IGT) and three inhibition measures (Go/NoGo task, MFFT, Stroop task) for our analysis. The IGT was used in our previous study [17].

\section{Measurements \\ Decision making measure: computerized animation variant of the lowa gambling test}

As a simulation of real-life decision-making, the IGT involves weighing expected, but uncertain, rewards and 
penalties (for review [40]). Diminished performance on the IGT expresses the participant's failing to learn from punishment cues, and ability to improve their decisions in the face of changing contingencies [40]. The IGT is a favored measure available to gauge risky decisions [22]. This test is presented in the form of a game (we used "Casino" AnimaScan Ltd., Ashdod, Israel, 2000 a computerized animation version of IGT [41]).

The IGT requires choosing between several different alternatives. Each trial has four decks of cards to choose from. The four decks of cards A, B, C, D were placed one beside the other simultaneously on a computer screen. Participants knew that teach deck gives them virtual money, however, they were unaware that $\mathrm{A}$ and $\mathrm{B}$ were termed risky, and their long-term results are negative, while $\mathrm{C}$ and $\mathrm{D}$ were safe decks with a more positive overall outcome. They gains were also varied. Participants were instructed that they had 100 options to choose from and their aim was to earn as much virtual money as possible. The choices (selection of cards from different decks) are either advantageous or disadvantageous, but each choice is associated with ambiguity regarding the outcome, since it is difficult for the subject to keep track and remember the gains and losses from previous trials [42]. In the beginning, the IGT simulates a specific situation "decisions under ambiguity". This means that subjects have no information about the choices' consequences and probabilities. Later, by using the feedback of previous choices, subjects can learn the rules (most likely after the first half of 100 trials), and, thus, the IGT assesses "decisions under risk." [42] Participants play the game several times and get results, and learn to choose the safe card decks over the risky ones. A 'net score' was calculated for the each participant according to deck selections [(A+B)- $(C+D)]$ [42]. Although the IGT's sensitivity for detecting decisionmaking impairment is well established, recent studies have highlighted the complexity of this task [28, 43, 44].

\section{Inhibition measures: the go/NoGo task}

Response inhibition can be defined as a cognitive action that enables a person to repress certain behaviors or reactions. The purpose of the Go/NoGo task is to estimate whether a behavior that is not appropriate can be controlled [45]. In this 5-min test, participants were given 120 red rectangles ('Go') and 30 black rectangles ('NoGo') and asked to complete 150 trials. Stimulus was presented in random order at a rate of one stimulus per $2000 \mathrm{~ms}$ and participants were told to respond to the stimuli with a Go or withhold response NoGo. A constant inter-stimulus interval was present for minimizing any orienting response caused by the unpredictability of a stimulus display. The Go/NoGo mean of response time (as sum of mean responses time of correct responses during the two blocks of the Go/NoGo task) was a measure of response inhibition ability. We applied a computerized variant of the Go/NoGo task (AnimaScan Ltd., Ashdod, Israel 2000) as previously described [46].

\section{MFFT}

The Matching Familiar Figures Task (MFFT) [36] was conducted in a computerized version [47] (AnimaScan Ltd., Ashdod, Israel 2000). Participants were directed to select the one (of six) possibility that matched the initial image. The following parameters were used: 1 . Response time in milliseconds; 2 . Number of errors committed during task.

\section{The Stroop task}

We use a manual key-press variant of the Stroop task [48] with unlimited time of stimulus presentation [49]. Subjects who are prone to impulsive behavior are expected to exhibit a weaker interference control, as proposed previously, [27, 50]. Participants were asked to read words and disregard the four font colors for words (green, red blue or yellow). The word is centered on a screen of a gray background printed in one of five colors: red, blue, green, yellow and black and is located above two colored rectangles on each side. Participants must press one of the two keys. The color of the word is always the same color of one of the rectangles and the other color is the meaning of the word. There were 40 'Neutral' trials where the letters of the words were black, 40 'Congruent' trials where the meaning of the word and the color of the letters corresponded and 40 'Incongruent' trials where the meaning of the word did not correspond to the colors of the letter (word BLUE written in red).

\section{Statistical analysis}

Data were analyzed using SPSS (v. 19) software for Windows. All analyses used two-tailed levels of significance. The parametric ( $t$-test) and non-parametric $\left(\chi^{2}\right)$ tests were performed to compare group differences in demographic and behavioral parameters. For evaluation of differences between groups in the inhibition performance, the multivariate analysis of covariance (MANCOVA) was conducted with performance variables (mean of response time, variability of response time, numbers of errors, et ctr) as dependent measures and group (tattooed women and controls) as between-subject measures, with education and smoking as covariates. A hierarchical regression was conducted to examinee if variables of our interest: (i) Stroop interference reaction time (response time in the incongruent condition minus response time in the congruent condition), (ii) the Go/NoGo mean of response time (as sum of mean responses time in the blocks of the Go/NoGo task), and (iii) the total number 
of errors in the MFFT explain a statistically significant amount of variance in the IGT performance (sum of a net score for the 40 last selections: Trials 60-100). Since participants with high impulsivity perform poorly in the IGT due to a robust learning component [42], we separated early and late IGT selections and used only the 40 last selections and combined them into a single measure. This analysis allows correction of the significance levels for multiple tests when two or more response variables are tested from the same set of individuals.

\section{Results}

Women with tattoos were significantly less educated $(14.53 \pm 2.77$ versus $15.82 \pm 2.63$ in non-tattooed women; $\mathrm{t}=2.60, \mathrm{df}=118, p=0.01)$ and with a higher of rate of smoking status $(55 \%$ versus $10 \% ; \mathrm{x} 2=27.69, \mathrm{df}=1, p<$ $0.0001)$ than non-tattooed women. No differences in age were found between the two groups $(28.47 \pm 5.42$ versus $28.35 \pm 5.95$ years; $\mathrm{t}=0.11, \mathrm{df}=118, p=0.91$ ). Thus education and smoking habit were considered as covariates.

The inhibition characteristics of the tattooed and nontattooed women are shown in Tables 1, 2 and 3. Significant between-group differences were not found for both MFFT and Stroop tasks in terms of response time, variability of response time and number of errors. However, the tattooed women performed significantly more slowly than non-tattooed women in the Go/NoGo task, indicating impaired response inhibition.

The effect of three inhibition measures on risky performance in the IGT was evaluated by the hierarchical regression analysis. The net score of the last two trials of the IGT (40 trials) was considered as the dependent variable. Three inhibition measures: (i) response inhibition (as sum of response time in the two blocks of the Go/ NoGo task), (ii) the total number of errors in the MFFT and (iii) Interference Index (Response Time of Incongruence Condition - Response time of Congruent Condition) in the Stroop task were considered as independent measures. The hierarchical regression analysis did not reveal significant main effects of any inhibition measures on the risky decision process (Table 4).

\section{Discussion}

Although impulsivity explains the relation between getting tattoo and increased risk- taking behavior, surprisingly this notion has received little empirical support. In contrast to our study, previous impulsivity studies in tattoo populations relied solely on self-report measures. The advantage of the current study is the use of three inhibition measures in order to clarify the contribution of several facets of risky behavior. The mechanisms involved in risky behavior in young non-criminal tattooed persons are not clear. Association between inhibition abilities and decision-making process is an important
Table 1 Multivariate Analysis of Covariance (MANCOVA) on the GoNoGo task

\begin{tabular}{llll}
\hline GoNoGo & Adjusted mean (SD) & F \\
\cline { 2 - 3 } & & \\
\hline Tattooed Control & & \\
\hline
\end{tabular}

\begin{tabular}{lll}
\hline Overall & & \\
Group & $2.23^{1}$ & $.03^{*}$ \\
Smoking & $2.53^{1}$ & $.01^{*}$ \\
Education & $1.02^{1}$ & .42
\end{tabular}

RT (part 1)

$\begin{array}{lllll}\text { Group } & 392.45(8.18) & 57.86(8.118) & 7.89 & .00^{*}\end{array}$

Smoking $\quad 2.20 \quad .14$

$\begin{array}{lll}\text { Education } & 2.86 & .09\end{array}$

SD of RT (part 1)

\begin{tabular}{|c|}
\hline \multirow{2}{*}{$\begin{array}{l}\text { Group } \\
\text { Smoking }\end{array}$} \\
\hline \\
\hline Education \\
\hline
\end{tabular}

Error of Omission (part 1)

\begin{tabular}{|c|c|c|c|}
\hline Group & $.49(1.18)$ & $.52(1.18)$ & .00 \\
\hline Smoking & & & .39 \\
\hline Education & & & .88 \\
\hline
\end{tabular}

Error of Commission (part 1)

$\begin{array}{lllll}\text { Group } & .75(.16) & 1.14(.16) & 2.40 & .12 \\ \text { Smoking } & & & 2.41 & .12 \\ \text { Education } & & & 1.57 & .21\end{array}$

RT (part 2)

$\begin{array}{llll}\text { Group } \quad 393.09(8.47) & 45.40(8.47) & 13.97 & 00^{* * *}\end{array}$

Smoking

Education

$8.47 .00^{* *}$

SD of RT (part 2)

$\begin{array}{lllll}\text { Group } & 83.28(5.03) & 66.14(5.03) & 5.12 & .02^{*}\end{array}$

Smoking

$4.71 \quad .03^{*}$

Education

$.46 \quad .49$

Error of Omission (part 2)

\begin{tabular}{|c|c|c|c|}
\hline Group & $.44(.16)$ & $.39(.16)$ & .03 \\
\hline Smoking & & & .25 \\
\hline Education & & & 1.16 \\
\hline
\end{tabular}

Error of Commission (part 2)

\begin{tabular}{|c|c|c|c|}
\hline Group & $.97(.019)$ & $1.49(.019)$ & 3.08 \\
\hline Smoking & & & 4.03 \\
\hline Education & & 2.79 & \\
\hline
\end{tabular}

Note. ${ }^{1}$ Wilks' Lambda F. Group $=$ tattooed vs. non-tattooed women. ${ }^{*} p<.05 .{ }^{* *} p<.01$. ${ }^{* * *} p<.001$. The means were adjusted by education and smoking habit that were considered as covariates. It is of note that in our previous study (Kertzman et al., 2015) smoking was considered as betweensubject factor in repeated measures analysis of covariance (ANCOVA) 
Table 2 Analysis of Covariance (MANCOVA) on Matching Familiar Figures Test (MFFT)

\begin{tabular}{|c|c|c|c|}
\hline \multirow[t]{2}{*}{ MFFT } & \multicolumn{2}{|c|}{ Adjusted mean (SD) } & \multirow[t]{2}{*}{$\mathrm{F}$} \\
\hline & Tattooed & Control & \\
\hline \multicolumn{4}{|l|}{ Overall } \\
\hline Group & & & $.57^{1}$ \\
\hline Smoking & & & $1.06^{1}$ \\
\hline Education & & & $1.57^{1}$ \\
\hline \multicolumn{4}{|l|}{ First RT } \\
\hline Group & $16.27(1.23)$ & $14.84(1.23)$ & .59 \\
\hline Smoking & & & .49 \\
\hline Education & & & 3.85 \\
\hline \multicolumn{4}{|l|}{ Mean RT } \\
\hline Group & $20.90(1.33)$ & $19.10(1.33)$ & .80 \\
\hline Smoking & & & 3.73 \\
\hline Education & & & 6.05 \\
\hline \multicolumn{4}{|l|}{ SD RT } \\
\hline Group & $13.55(1.07)$ & $12.01(1.07)$ & .89 \\
\hline Smoking & & & 5.27 \\
\hline Education & & & 5.75 \\
\hline \multicolumn{4}{|l|}{ Error } \\
\hline Group & $3.81(.39)$ & $3.90(.39)$ & .02 \\
\hline Smoking & & & 1.37 \\
\hline Education & & & 1.08 \\
\hline \multicolumn{4}{|l|}{ Error RT } \\
\hline Group & $20.98(2.29)$ & $23.47(2.29)$ & .52 \\
\hline Smoking & & & .27 \\
\hline Education & & & .37 \\
\hline \multicolumn{4}{|l|}{ Error SD } \\
\hline Group & 7.39 (1.09) & $8.94(1.09)$ & .89 \\
\hline Smoking & & & .25 \\
\hline Education & & & .75 \\
\hline
\end{tabular}

issue and its investigation can shed a light on the selfcontrol in tattooed population.

The first main hypothesis of our current study was that tattooed women would exhibit risky behavior as a result of impaired inhibition capacities. Inhibition impairments were expected in tattooed population more frequently than in non-tattooed population since tattooing behavior was reported to be associated with wide range of risk taking behaviors and substance use disorders (see introduction). Analysis of the different inhibition processes may lead to a better understanding of risky behavior. Tattooed women did not display deficits in tasks measured reflexive inhibition and interference control, but impaired response inhibition as measured by the slow response time in the Go/NoGo task. In the Go/NoGo task, response slowness was a sensitive
Table 3 Analysis of Covariance (MANCOVA) on Stroop test

\begin{tabular}{|c|c|c|c|c|}
\hline \multirow[t]{2}{*}{ Stroop } & \multicolumn{2}{|l|}{ Adjusted mean } & \multirow[t]{2}{*}{$\mathrm{F}$} & \multirow[t]{2}{*}{$P$} \\
\hline & Tattooed & Control & & \\
\hline \multicolumn{5}{|l|}{ Overall } \\
\hline Group & & & $28^{1}$ & .97 \\
\hline Smoking & & & $1.11^{1}$ & .36 \\
\hline Education & & & $1.40^{1}$ & .19 \\
\hline \multicolumn{5}{|l|}{ Neutral RT } \\
\hline Group & $1031.40(25.33)$ & $1049.92(25.33)$ & .23 & .62 \\
\hline Smoking & & & .52 & .47 \\
\hline Education & & & .14 & .70 \\
\hline \multicolumn{5}{|l|}{ Neutral SD } \\
\hline Group & $299.24(17.19)$ & $297.00(17.19)$ & .00 & .93 \\
\hline Smoking & & & 1.28 & .26 \\
\hline Education & & & .01 & .91 \\
\hline \multicolumn{5}{|l|}{ Neutral Errors } \\
\hline Group & $.17(.07)$ & $.27(.07)$ & .69 & .40 \\
\hline Smoking & & & 3.42 & .06 \\
\hline Education & & & .08 & .76 \\
\hline \multicolumn{5}{|c|}{ Congruent RT } \\
\hline Group & $926.80(24.78)$ & 952.49 (24.78) & .47 & .49 \\
\hline Smoking & & & 1.01 & .31 \\
\hline Education & & & .05 & .81 \\
\hline \multicolumn{5}{|c|}{ Congruent SD } \\
\hline Group & $273.04(20.40)$ & $282.28(20.40)$ & .09 & .76 \\
\hline Smoking & & & 1.78 & .18 \\
\hline Education & & & .32 & .57 \\
\hline \multicolumn{5}{|c|}{ Congruent Errors } \\
\hline Group & $.12(.06)$ & $.21(.06)$ & .76 & .38 \\
\hline Smoking & & & 1.02 & .31 \\
\hline Education & & & 3.28 & .07 \\
\hline
\end{tabular}

Incongruent RT

$\begin{array}{lllll}\text { Group } & 1147.70(28.12) & 1164.86(28.12) & .16 & .68 \\ \text { Smoking } & & & 1.26 & .26 \\ \text { Education } & & & .67 & .41\end{array}$

Incongruent SD

$\begin{array}{lllll}\text { Group } & 334.84(18.76) & 329.18(18.76) & .04 & .84 \\ \text { Smoking } & & & .17 & .67 \\ \text { Education } & & & .36 & .54\end{array}$

Incongruent Errors

$\begin{array}{lllll}\text { Group } & 1.97(.36) & 2.29(.36) & .34 & .56 \\ \text { Smoking } & & & 1.06 & .30 \\ \text { Education } & & & 94 & .33\end{array}$

Note. ${ }^{1}$ Wilks' Lambda F. Group $=$ tattooed vs. non-tattooed women. ${ }^{*} \mathrm{p}<.05$. ${ }^{* *} \mathrm{p}<.01 .{ }^{* * *} \mathrm{p}<.001$ 
Table 4 Summary of hierarchical linear regression analysis for variables predicting net-score in the IGT

\begin{tabular}{|c|c|c|c|c|c|c|c|c|c|}
\hline \multirow[b]{2}{*}{ Variable } & \multicolumn{3}{|c|}{ Model 1} & \multicolumn{3}{|c|}{ Model 2} & \multicolumn{3}{|c|}{ Model 3} \\
\hline & $B$ & $S E B$ & $\beta$ & $B$ & $S E B$ & $\beta$ & $B$ & $S E B$ & $\beta$ \\
\hline \multicolumn{10}{|l|}{ GoNoGo } \\
\hline Education & .69 & 1.40 & .04 & .15 & 1.36 & .01 & .24 & 1.40 & .01 \\
\hline Smoking & -2.52 & 2.81 & -.08 & 2.64 & 3.05 & .09 & 2.74 & 3.09 & .09 \\
\hline Tattoo & & & & -10.08 & 2.83 & $-.37^{* *}$ & -15.26 & 18.80 & -.56 \\
\hline Sum RT & & & & .00 & .00 & .12 & .00 & .00 & .09 \\
\hline Tattoo X Sum RT & & & & & & & .00 & .01 & .20 \\
\hline$R^{2}$ & .01 & & & .11 & & & .11 & & \\
\hline$F$ for change in $R^{2}$ & .75 & & & $6.37^{* *}$ & & & .07 & & \\
\hline \multicolumn{10}{|l|}{ MFFT } \\
\hline Education & & & & .39 & 1.36 & .02 & .56 & 1.36 & .03 \\
\hline Smoking & & & & 1.92 & 3.04 & .06 & 1.25 & 3.08 & .04 \\
\hline Tattoo & & & & -8.95 & 2.73 & $-.33^{* *}$ & -12.89 & 4.09 & $-.47^{* *}$ \\
\hline Error & & & & -.05 & .42 & -.01 & -.65 & -.63 & -.13 \\
\hline Tattoo X Error & & & & & & & 1.12 & .86 & .24 \\
\hline$R^{2}$ & & & & .09 & & & .11 & & \\
\hline$F$ for change in $R^{2}$ & & & & $5.35^{* *}$ & & & 1.67 & & \\
\hline \multicolumn{10}{|l|}{ Stroop } \\
\hline Education & & & & .21 & 1.36 & .01 & .38 & 1.33 & .02 \\
\hline Smoking & & & & 1.7 & 3.01 & .05 & 1.77 & 3.02 & .06 \\
\hline Tattoo & & & & -8.82 & 2.72 & $-.32^{* *}$ & -13.58 & 6.30 & $-.50^{*}$ \\
\hline Interference RT & & & & -.01 & .01 & -.10 & -.02 & .01 & -.17 \\
\hline \multicolumn{10}{|l|}{ Tattoo X } \\
\hline Interference RT & & & & & & & .02 & .02 & .21 \\
\hline$R^{2}$ & & & & .10 & & & .11 & & \\
\hline$F$ for change in $R^{2}$ & & & & $6.04^{* *}$ & & & .70 & & \\
\hline
\end{tabular}

Note. ${ }^{*} p<.05 .{ }^{* *} p<.01$

measure of inhibition impairment [51]. Impairment in the Go/NoGo performance, but not in the MFFT and the Stroop tasks performance, indicates that tattooed women show inhibition impairments in situations under time pressure only.

The second hypothesis of the current study was that tattooed women would exhibit risky decisions as a result of impaired inhibition capacity. Impulsive responses (faster with more errors) reflect reduced behavior monitoring efficiency and inhibition control that are expected when greater reward sensitivity is required [52]. In our study we did not find an association between fast-error performance on inhibition task and risky decision on the IGT. Contrary to our prediction, the hierarchical regression analysis did not reveal any significant main effects of the three inhibition measures on the IGT performance. Bechara [53] suggested that in contrast to a learned inhibition of a pre-potent response decisionmaking process involves an evaluation of the pros and cons of a given response options. A recent meta-analysis showed that healthy populations are not unequivocally good decision makers [54] and that a more than $30 \%$ of "normal" controls perform poorly on the IGT [55]. It is possible that the IGT (as measure of risky process of decision) may be a multi-dimensional task requiring several processes, including reversal learning, response inhibition, risk-seeking and deficits in strategic planning, cognitive biases, and hypersensitivity to reward [56]. It seems that the IGT assesses behavior in a fashion that combines multiple cognitive functions [57]. Executive functioning and working memory skills are important components of IGT performance, even in those without clinical disorders or evidence of "real world" dysfunction [55]. Moreover, the IGT reflects also an affective component of risk-taking decision [58]. In addition, it is possible that risky decisions may endure multiple mechanisms beyond disinhibition - such as "faulty cognition" and "false beliefs", [24] sensation seeking [28] and negative mood [59]. Increased risk-taking behavior and decreased use of contextual information has been 
observed when affective aspects of decision-making are engaged [60].

Tattooed young women shows a preserved reflexive inhibition and interference control while express the impaired response inhibition. In current study, we aimed to assess the role of impaired inhibition control in risky decisions among tattooed persons. Although, it is likely that several of inhibition facets may contribute differentially to risky behavior all three investigated inhibition pathways not accounted for the variance in the relation between risky decision and tattooing behavior.

\section{Conclusions}

This study defined the behavioral and impulse-dimension attributes of young women with tattoos. The strengths of the present study include the evaluation of a population of young women with limited number of tattoos, absence of: criminal or antisocial behavior, unemployment and substance use disorders, as well as using standard cognitive performance tasks that compared risk-taking decisions with different inhibition-related tasking challenges. The major limitation of the present study is the inclusion of healthy population of women only, which confers the advantage of relative homogeneity, but limits the generalizability to the general tattooed population. Unfortunately, only three inhibition paradigms were used in this study. More measures/domains of inhibition (e.g. reward paradigm of inhibition, waiting ability, "interruptive inhibition" of ongoing responses) should be assessed in an attempt to clarify the association between inhibition control and risky decision in tattooed women.

This study was designed to clarify the associations between inhibition ability and decision making process among young tattooed women. Inhibition capacities of tattooed women are preserved except slowness in the Go/NoGo task. Thus, it appears that risky decision in tattooed women is not a direct consequence of impaired inhibition capacities.

It may be concluded that risk-taking decisions as assessed in the IGT (hot EF) and inhibition abilities (cool EF) are different and independent aspects of selfcontrol, as was suggested in previous studies in nontattooed population [26-31, 41]. It should be noted that in the absence of a cutoff value for the IGT performance, the current analysis shows that the tattooed group had a significantly lower score than non-tattooed women ("group differences"), but the results cannot indicate an "impairment" in decision-making.

The limited research in tattooing persons, justifies further studies that will explore the multiple aspects of possible association between inhibition capacities and risky decisions, including variables such as the number of tattoos, their size and body localization, as well as their psychological meaning.

\section{Abbreviations}

AK: Alexandr Kagan; AW: Abraham Weizman; IGT: lowa Gambling Test; MFFT: Matched Familiar Figure Test; $\mathrm{OH}$ : Omer Hegedish; RL: Rina Lapidus; SK: Semion Kertzman

\section{Acknowledgements}

Not applicable.

\section{Endnotes}

This article is part of Dr. Alex Kagan's PhD thesis: "Cognitive and Psychological Mechanisms of the Risk Decisions among Women with Tattoos" carried out under the supervision of Prof. Rina Lapidus, and Prof. Abraham Weizmam and with the consultation of Dr. Semion Kertzman conducted in the Program for Hermeneutics and Cultural Studies of the Interdisciplinary Studies Unit at BarIlan University, Ramat Gan, Israel.

\section{Authors' contributions}

All authors have read and approved the manuscript, and ensure that this is the case. SK-Conceptualization, Methodology, Project Administration, WritingOriginal Draft Preparation; AK- Conceptualization, Investigation, WritingOriginal Draft Preparation; $\mathrm{OH}$ - Formal analysis; RL- Conceptualization, Supervision; AW- Conceptualization, Supervision, Writing-Original Draft Preparation, Writing-Review and Editing.

\section{Funding}

Neither financial nor material support was received from any external resource for this work. One of the authors of this study, Dr. Kertzman is employed by Anima Scan Ltd. but his employment is unrelated to the current study and his salary is in no way compensation for any work done on this study. Additionally, Anima Scan Ltd. did not provide any financial support for this study in any form. Neither did Anima Scan Ltd. play a role in the study design, data collection and analysis, decision to publish, or preparation of the manuscript.

Neither financial nor material support was received from any external resource for this work.

\section{Availability of data and materials}

The datasets used and/or analysed during the current study are available from the corresponding author on reasonable request.

\section{Ethics approval and consent to participate}

The study was approved by the Bar-Ilan University Ethics committee/Review Board (Ramat Gan, Israel) on February, 2012. The 120 participants have signed a written consent form to be part of this current free study.

\section{Consent for publication}

Not Applicable.

\section{Competing interests}

SK is an employee of Anima Scan Ltd., however Anima Scan Ltd., did not provide any funding and/or materials for the present study and did not have any role in study design, data collection and analysis, decision to publish, or preparation of the manuscript.

This does not alter our adherence to BMC Psychology policies on sharing data and materials.

\footnotetext{
Author details

'Beer-Ya'akov-Ness Ziona Mental Health Center, Forensic Psychiatry Division, Ness Ziona, Israel. '2Sackler Faculty of Medicine, Tel Aviv University, Tel Aviv, Israel. ${ }^{3}$ The Program for Hermeneutics and Cultural Studies, Interdisciplinary Studies Unit, Bar-Ilan University, Ramat Gan, Israel. ${ }^{4}$ Department of Neuro-Pathopsychology, L.S. Vygotsky Institute of Psychology, RSUH, Moscow, Russia. ${ }^{5}$ Ashkelon Academic College, Ashkelon, Israel. ${ }^{6}$ Department of Psychology, University of Haifa, Haifa, Israel. ${ }^{7}$ Comparative Literature Department, Bar-Ilan University, Ramat Gan, Israel. ${ }^{8}$ Research Unit, Geha Mental Health Center and Felsenstein Medical Research Center, Petah Tikva, Israel.
} 
Received: 23 May 2019 Accepted: 5 December 2019

Published online: 23 December 2019

\section{References}

1. Arnett JJ. Emerging adulthood: a theory of development from the late teens through the twenties. Am Psychol. 2000;55:469-80.

2. Bhargava $S$, Singh R, Kumari K. Significance of tattoo marks in forensic psychology: a review. Int J Curr Adv Res. 2016;5(4):857-9.

3. Roggenkamp H, Nicholls A, Pierre JM. Tattoos as a window to the psyche: how talking about skin art can inform psychiatric practice. World J Psychiatry. 2017;7(3):148-58.

4. Isaacs T, Ngwanya RM, Lehloenya RJ. Tattoos: a summary knowledge for the practicing clinician. SAMJ. 2018;108(9):714-20.

5. Guéguen N. Tattoos, piercings, and sexual activity. Soc Behav Personal Int J. 2012:40(9):1543-7.

6. King K, Vidourek R. Getting inked: tattoo and risky behavioral involvement among university students. Soc Sci J. 2013;50(4):540-6.

7. Komar D, Lathrop S. Tattoo types and frequencies in New Mexican white hispanics and white non-hispanics: autopsy data from homicidal and accidental deaths, 2002-2005. Am J Foren Med Path. 2008:29:285-9.

8. Katsos K, Moraitis K, Papadodima S, Spiliopoulou C. Tattoos and abuse of psychoactive substances in an autopsy population sample from Greece. Rom J Leg Med. 2018;26:21-8.

9. Byard RW, Charlwood C. Commemorative tattoos as markers for anniversary reactions and suicide. J Forensic Legal Med. 2014;24:15-7.

10. Owen DC, Armstrong ML, Koch JR, Roberts AE. College students with body art: well-being or high-risk behavior? J Psychosoc Nurs Men. 2013;51:20-8.

11. Stirn A, Oddo S, Peregrinova L, Philipp S, Hinz A. Motivations for body piercings and tattoos the role of sexual abuse and the frequency of body modifications. Psychiatry Res. 2011;190:359-63.

12. Dukes RL. Deviant ink: a meta-analysis of tattoos and drug use in general populations. Deviant Behav. 2016;37(6):665-78

13. Jennings WG, Fox BH, Farrington DP. Inked into crime? An examination of the causal relationship between tattoos and life-course offending among males from the Cambridge study in delinquent development. J Crim Just. 2014;42(1):77-84.

14. Larson G, Patterson M, Markham L. A deviant art: tattoo-related stigma in an era of commodification. Psychol Mark. 2014;31(8):670-81.

15. Heywood W, Patrick K, Smith AM, Simpson JM, Pitts MK, Richters J, et al. Who gets tattoos? Demographic and behavioral correlates of ever being tattooed in a representative sample of men and women. Ann Epidemiol. 2012;22:51-6.

16. Carson HJ. The medium not the message: how tattoos correlate with early mortality. Am J Clin Pathol. 2014;142:99-103.

17. Kertzman S, Kagan A, Vainder M, Lapidus R, Weizman A. Interactions between risky decisions, impulsiveness and smoking in young tattooed women. BMC Psychiatry. 2013;2013:278.

18. Tate JC, Shelton BL. Personality correlates of tattooing and body piercing in a college sample: the kids are alright. Personal Individ Differ. 2008:45:281-5.

19. Güngör B, Budak E, Taymur I, Zorlu N, Ucgun B, Akgul A, Demirci H. The comparison of risky and ambiguity decision making and cool executive functions between patients with obsessive compulsive disorder and healthy controls. Arch Clin Psychiatry (São Paulo). 2018;45(5):112-8.

20. Billieux J, Gay P, Rochat L, van der Linden N. The role of urgency and its underlying psychological mechanisms in problematic behaviors. Behav Res Ther. 2010:48:1085-96.

21. Noël X, Bechara A, Dan B, Hanak C, Verbanck P. Response inhibition deficit is involved in poor decision making under risk in nonamnesic individuals with alcoholism. Neuropsychology. 2007;21:778-86.

22. Brevers D, Bechara A, Cleeremans A, Noël X. lowa gambling task (IGT): twenty years after - gambling disorder and IGT. Front Psychol. 2013;4:1-14.

23. Cassotti M, Moutier S. How to explain receptivity to conjunction fallacy inhibition training: evidence from the lowa gambling task. Brain Cogn. 2010;72:378-84

24. Kahneman D, Tversky A, editors. Choices, values, and frames. New York/ Cambridge, UK: Russell Sage Foundation/Cambridge University Press; 2000

25. Sharot T. The optimism bias: a tour of the irrationally positive brain. 1st ed. New York: Pantheon Books; 2011

26. Toplak ME, Sorge GB, Benoit A, West RF, Stanovich KE. Decision-making and cognitive abilities: a review of associations between lowa gambling task performance, executive functions, and intelligence. Clin Psychol Rev. 2010;30:562-81.
27. Morris TM, Hudson JL, Dodd HF. Risk-taking and inhibitory control in behaviourally inhibited and disinhibited preschool children. Personal Individ Differ. 2014;71:113-7.

28. Buelow MT, Suhr JA. Construct validity of the lowa gambling task. Neuropsychol Rev. 2009;19:102-14

29. Fernie G, Cole JC, Goudie AJ, Field M. Risk-taking but not response inhibition or delay discounting predict alcohol consumption in social drinkers. Drug Alcohol Depend. 2010;112:54-61.

30. Kertzman S, Fluhr A, Vainder M, Weizman A, Dannon PN. The role of gender in association between inhibition capacities and risky decision making. Psychol Res Behav Manag. 2018;11:503-10.

31. LeGris J. Rapid emotional response and disadvantageous lowa gambling task performance in women with borderline personality disorder. Bord Personal Disord Emot Dysregul. 2018;5:16.

32. Sun DL, Chen ZJ, Ma N, Zhang XC, Fu XM, Zhang DR. Decision-making and prepotent response inhibition functions in excessive internet users. CNS Spectr. 2009;14:75-81.

33. Demos KE, Hart CN, Sweet LH, Mailloux KA, Trautvetter J, Williams SE, et al. Partial sleep deprivation impacts impulsive action but not impulsive decision-making. Physiol Behav. 2016;164:214-9.

34. Cooper SE, Goings SP, Kim JY, Wood RI. Testosterone enhances risk tolerance without altering motor impulsivity in male rats. Psychoneuroendocrinology. 2014;40:201-12

35. Bari A, Robbins TW. Inhibition and impulsivity: behavioral and neural basis of response control. Prog Neurobiol. 2013;108:44-79.

36. Kagan J, Rosman BL, Day D, Albert J, Phillips W. Information processing in the child: significance of analytic and reflective attitudes. Psychol Monogr Gen Appl. 1964;78(1):1-37.

37. Hong BK, Lee HY. Self-esteem, propensity for sensation seeking, and risk behaviour among adults with tattoos and piercings. J Public Health Res 2017;6(3):1107.

38. Ruffle BJ, Wilson AE. Tat will tell: tattoos and time preferences. J Econ Behav Organ. 2019;166:566-85

39. Kertzman S, Kagan A, Hegedish O, Lapidus R, Weizman A. Do young women with tattoos have lower self-esteem and body image than their peers without tattoos? A non-verbal repertory grid technique approach. Plose One. 2019;14(1):e0206411.

40. Jones KA, Hewson TS, CP, Khalifa N. A systematic review and meta-analysis of decision-making in offender populations with mental disorder. Neuropsychol Rev. 2019;29(2):244-58.

41. Kertzman S, Lidogoster H, Aizer A, Kotler M, Dannon PN. Risk-taking decisions in pathological gamblers is not a result of their impaired inhibition ability. Psychiatry Res. 2011;188:71-7.

42. Bechara A. lowa gambling task professional manual. Psychological Assessment Resources: Lutz: 2007.

43. Brand M, Recknor EC, Grabenhorst F, Bechara A. Decisions under ambiguity and decisions under risk: correlations with executive functions and comparisons of two different gambling tasks with implicit and explicit rules. J Clin Exp Neuropsychol. 2007:29:86-99.

44. Dunn BD, Dalgleish T, Lawrence AD. The somatic marker hypothesis: a critical evaluation. Neurosci Biobehav R. 2006;30:239-71.

45. Nigg JT. Annual research review: on the relations among selfregulation, self-control, executive functioning, effortful control, cognitive control, impulsivity, risk-taking, and inhibition for developmental psychopathology. J Child Psychol Psychiatry. 2017:58:361-83.

46. Kertzman S, Lowengrub K. Aizer a, Vainder M, Kotler M, Dannon PN (2008). Go-nogo performance in pathological gamblers. Psychiatry Res. 2008;161:1-10.

47. Kertzman S, Vainder M, Vishne T, Aizer A, Kotler M, Dannon P. Speed accuracy tradeoff in decision making performance among pathological gamblers. Eur Addict Res. 2010;16:23-30.

48. MacLeod CM. Half of century of research on the Stroop effect: an integrative review. Psychol Bull. 1991;109:163-203.

49. Kertzman S, Lowengrub K, Aizer A, Ben Nahum Z, Kotler M, Dannon P. Stroop performance in pathological gamblers. Psychiatry Res. 2006;142:1-10.

50. Cheng ASK, Lee HC. Risk-taking behavior and response inhibition of commuter motorcyclists with different levels of impulsivity. Transport Res F: Traf. 2012;15:535-43.

51. Cheung AM, Mitsis EM, Halperin JM. The relationship of behavioral inhibition to executive functions in young adults. J Clin Exp Neuropsychol. 2004;26:393-404. 
52. Martin LE, Potts GF. Reward sensitivity in impulsivity. Neuroreport. 2004; 15(9):1519-22.

53. Bechara A. Risky business: emotion, decision-making, and addiction. J Gambl Stud. 2003;19:23-51.

54. Steingroever H, Wetzels R, Horstmann A, Neumann J, Wagenmakers EJ. Performance of healthy participants on the lowa gambling task. Psychol Assess. 2013;25:180-93.

55. Suhr JA, Hammers D. Who fails the lowa gambling test (IGT)? Personality, neuropsychological, and near-infrared spectroscopy findings in healthy young controls. Arch Clin Neuropsychol. 2010;25:293-302.

56. Barack DL, Platt ML. Neurocomputational nosology: malfunctions of models and mechanisms. Front Psychol. 2016;7:602.

57. Schrag Y, Tremea A, Lagger C, Ohana N, Mohr C. Pro free will priming enhances "risk-taking" behavior in the lowa Gambling Task, but not in the Balloon Analogue Risk Task: Two independent priming studies. Plos One. 2016:11(3):e0152297.

58. Rosenbaum GM, Hartley CA. Developmental perspectives on risky and impulsive choice. Philos Trans R Soc B. 2018;374(1766):20180133.

59. Suhr JA, Tsanadisa J. Affect and personality correlates of the lowa gambling task. Personal Individ Differ. 2007;43:27-36.

60. Figner B, Weber EU, Mackinlay RJ, Wilkening F. Affective and deliberative processes in risky choice: age differences in risk taking in the Columbia card task. J Exp Psychol Learn Mem Cogn. 2009;35:709-30

\section{Publisher's Note}

Springer Nature remains neutral with regard to jurisdictional claims in published maps and institutional affiliations.

- fast, convenient online submission

- thorough peer review by experienced researchers in your field

- rapid publication on acceptance

- support for research data, including large and complex data types

- gold Open Access which fosters wider collaboration and increased citations

- maximum visibility for your research: over $100 \mathrm{M}$ website views per year

At $\mathrm{BMC}$, research is always in progress.

Learn more biomedcentral.com/submissions 